\title{
INCLUSÃO E APRENDIZAGEM COMO IMPERATIVOS DA GOVERNAMENTALIDADE NEOLIBERAL E A CRIAÇÃO DOS INSTITUTOS FEDERAIS DE EDUCAÇÃO NO BRASIL
}

\author{
INCLUSIÓN Y APRENDIZAJE COMO IMPERATIVOS DE LA \\ GOVERNAMENTABILIDADE NEOLIBERAL Y LA CREACIÓN DE LOS \\ INSTITUTOS FEDERALES DE EDUCACIÓN EN BRASIL
}

INCLUSION AND LEARNING AS IMPERATIVES OF THE NEOLIBERAL GOVERNMENTALITY AND THE CREATION OF FEDERAL INSTITUTES OF EDUCATION IN BRAZIL

\author{
Beatris GATTERMANN ${ }^{1}$ \\ Leandra Boer POSSA ${ }^{2}$
}

RESUMO: O presente estudo se insere no campo de investigação das políticas de inclusão na educação profissional e pode ser inscrito entre os estudos que se servem de uma perspectiva pós-estruturalista a partir dos Estudos Foucaultianos, especialmente da noção de governamentalidade, para procedimento e desenvolvimento analítico. Objetivamos identificar, em documentos internacionais, como a adoção da inclusão, na forma de determinação das condições para a educação na atualidade, pode ser explicitada na ordem da governamentalidade neoliberal, construindo as condições para a criação dos Institutos Federais de Educação (IFs). Para tal empreendimento, tomamos como material analítico documentos políticos e de orientação produzidos pelos organismos internacionais entre a década de 1990 e os anos 2000. Com este movimento, percebemos que o investimento na política de expansão da educação profissional no Brasil, com a criação dos IFs, pode se inserir em uma forma de governamento em que sua função, como instituição de Estado, pode ser a de produzir um modo de condução e captura dos jovens e, com isso, assegurar uma perspectiva de inclusão que toma como referência o espaço da instituição como fronteira para classificar, identificar e controlar modos de ser da juventude, determinando modelos de aprender.

PALAVRAS-CHAVE: Inclusão. Governamentalidade. Educação profissional. Institutos Federais de Educação.

RESUMEN: El presente estudio hace parte del campo de investigación de las políticas de inclusión en la educación profesional y se puede inscribir entre los estudios que se sirven de una perspectiva pos-estructuralista partiendo de los estudios de Foucault, en

${ }^{1}$ Instituto Federal Farroupilha (IFFARROUPILHA), Santa Maria - RS - Brasil. Pedagoga no Instituto Federal Farroupilha Campus Santo Augusto - RS. Membro Grupo de Estudo Pesquisa em Educação Especial e Inclusiva - GEPE/UFSM e membro do Grupo de pesquisa GEPEE - IFFar. ORCID: <http://orcid.org/0000-0001-6700-0804>. E-mail: beatris.gattermann@iffarroupilha.edu.br

${ }^{2}$ Universidade Federal de Santa Maria (UFSM), Santa Maria - RS - Brasil. professora adjunta da Universidade Federal de Santa Maria e realizando estágio Pós doutoral (CAPES) na Faculdad de Filosofia e Ciencias da Educación, Departamento de Educación Comparada, da Universidad de Valencia, Espanha. ORCID: <http://orcid.org/0000-0001-6833-7572>. E-mail: leandrabp@gmail.com 
especial de la noción de governamentalidade, para procedimiento y desarrollo de análisis. El objetivo es identificar, en documentos internacionales, como la adopción de la inclusión, como una manera de determinar condiciones para la educación en la actualidad, se puede hacer explícita en el orden de la governamentalidade neoliberal, construyendo condiciones para la creación de los Institutos Federales de Educación (IFs). Para esta tentativa, buscamos analizar documentos políticos y de orientación producidos por los órganos internacionales, entre los años de 1990 y 2000. Con tal movimiento, percibimos que el investimento en la política de expansión de la educación profesional en Brasil, con la creación de los IFs, puede ser la de producción de una manera de conducir y atraer los jóvenes y, así, garantizar una perspectiva de inclusión que posee como referencia el espacio de la institución como limite para ordenar, identificar y vigilar modos de ser de la juventud determinando ejemplos de aprendizaje.

PALABRAS CLAVE: Inclusión. Governamentalidade. Educación professional. Intitutos federales de educación.

ABSTRACT: The present study is part of the research on inclusion policies in professional education and can be included among studies that use a post-structuralist perspective from the Foucaultian Studies, especially from the notion of governmentality, for analytical procedure and development. We aim to identify, in international documents, how the adoption of inclusion, in the form of determination of the conditions for education in the present time, can be set out in the order of neoliberal governmentality, building the conditions for the creation of the Federal Institutes of Education (FIs). For this purpose, we take as analytical material, policy and guidance documents produced by international organizations between the 1990s and the 2000s. With this movement, we realize that the investment in the policy of expanding professional education in Brazil, with the creation of FIs, can be inserted into a form of governance in which its function as a state institution may be to produce a way of conducting and capturing the young people and, with this, to ensure an inclusion perspective that takes as reference the space of the institution as a frontier for classifying, identifying, and controlling ways of being of particular youth models of learning.

KEYWORDS: Inclusion. Governmentality. Professional education. Federal Institutes of Education.

As reformas, a expansão e a (re)criação de Institutos Federais de Educação, Ciência e Tecnologia (IFs) como lócus da educação profissional no Brasil, nos últimos anos, nos leva a empreender um estudo que tem como objetivo identificar em alguns documentos internacionais o imperativo da inclusão e a narrativa da aprendizagem como determinação das condições para a educação profissional. Esta, pela ordem da governamentalidade neoliberal, tem construído as condições para reformas na educação 
profissional e a criação dos Institutos Federais de Educação e consequente atuação desses na Educação Básica de nível médio integrado com a educação profissional.

Os Institutos Federais de Educação Profissional, criados através da Lei $\mathrm{n}^{\circ}$ 11.892, de 29 de dezembro de 2008, têm como uma das finalidades a oferta de "educação profissional e tecnológica, em todos os seus níveis e modalidades, formando e qualificando cidadãos com vistas na atuação profissional nos diversos setores da economia, com ênfase no desenvolvimento socioeconômico local, regional e nacional" (Brasil, 2008, Art. 06).

É possível identificar que a criação dos IFs está articulada com as políticas educacionais desenvolvidas entre os anos de 2002 e 2014 no Brasil, nos governos de Luiz Inácio Lula da Silva e Dilma Rousseff, tendo em vista a prioridade dada à expansão da educação profissional e um projeto de inclusão social que toma como espaço primordial a educação. Isso pode ser comprovado na figura abaixo.

Figura 1 - Expansão da Rede Federal de Educação Profissional no Brasil

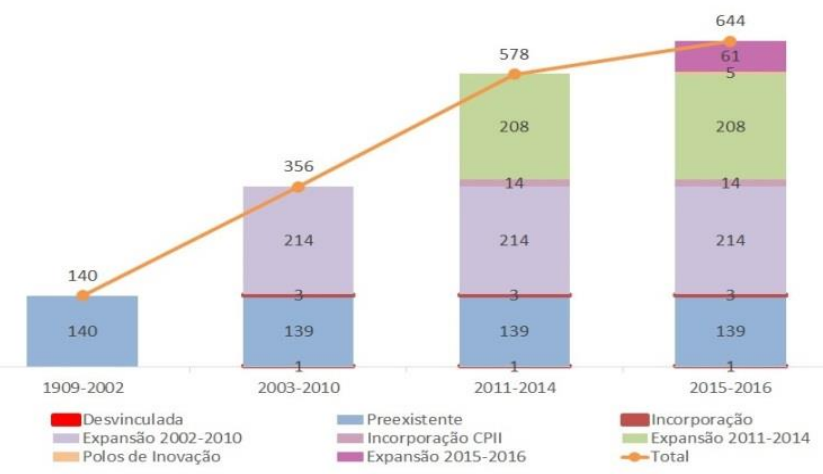

Fonte: MEC (2016) Expansão da Rede Federal de Educação Profissional, Científica e Tecnológica - em unidades (http://redefederal.mec.gov.br/expansao-da-rede-federal).

As diretrizes que orientam a expansão da Rede Federal e a criação de Institutos Federais priorizam a implantação de campus em "periferias de metrópoles e em municípios interioranos distantes de centros urbanos, em que os cursos estivessem articulados com as potencialidades locais de geração de trabalho" (BRASIL, 2010, p. 14). Esse movimento tem a intenção de incluir os jovens de cidades e de todas as regiões do Brasil na educação profissional, dimensionando, em cada canto do país: a Educação de Todos sem discriminação, a inclusão de todos e a responsabilidade do Estado, assumida a partir das relações internacionais e com os organismos 
internacionais, com políticas públicas de educação e desenvolvimento dos indivíduos para o desenvolvimento econômico e social do país.

Temos, assim, os IFs como instituições criadas e alocadas dentro de um conjunto de instituições que atuam para dar conta de questões sociais, econômicas e tecnológicas e formar sujeitos para um modo de vida contemporâneo, para um mercado de trabalho globalmente articulado e que têm na tecnologia e no conhecimento um dos seus principais acentos.

A necessidade de capacitar os indivíduos para que passem a se mover na lógica de aprender, acompanhar as tecnologias, produzir, consumir e manter o motor econômico funcionando implica colocar os indivíduos em movimento, circulando, produzindo, consumindo mais potentemente.

A criação dos IFs se constitui em uma ação institucional desenhada para operar a inclusão em diferentes regiões do país. Nenhuma região pode ficar fora, os jovens necessitam de formação para entrar no jogo econômico. Trata-se de uma instituição de educação profissional colocada em regiões onde dados do IBGE, das avaliações externas e dos índices produzidos apontam para a necessidade de estratégia de governamento da população, de gerenciamento do risco em relação à vulnerabilidade social, econômica e produtiva.

Parece existir, portanto, uma ligação entre investimentos do Estado em políticas de educação profissional e uma tática de alocação institucional em determinados espaços geográficos e discursivos para que as instituições de educação profissional possam operar o condicionamento de um modo de vida para que todos tenham a possibilidade de incluir-se no jogo produtivo-econômico.

Incluir e incluir-se é parte do jogo em que "uma das principais regras do jogo neoliberal: a inclusão de todos" (LOCKMANN, 2013, p. 33) coloca em funcionamento uma tática de atuação do Estado através da educação. Uma tática que se observa com a ampliação da Rede Federal de Educação Profissional, sendo esta uma possibilidade de viabilizar a captura de jovens e uma política que, ao mesmo tempo em que se constitui em prevenção e em gerenciamento do risco, é uma política de governamento da população.

Isso se confirma ao consultar a página da Secretaria de Educação Profissional e Tecnológica (SETEC) (consulta feita em maio de 2017). Os dados lá encontrados mostram que os IFs estão distribuídos por 568 cidades do Brasil, totalizando 644 campi e uma ampliação de matrículas no ensino médio integrado à educação técnica, que, em 
2008, era de 77.074, e, em 2013, ampliou-se para 534.853 ( $37^{\text {a }}$ Reunião Ordinária do Conif, 2013).

Este investimento tem relação direta com análises e projeções realizadas pelos organismos internacionais para o Brasil, e mostrar essa relação, pelo menos em parte, é um dos objetivos deste estudo, que consiste em identificar em documentos internacionais como a adoção da inclusão, na forma de determinação das condições para a educação na atualidade, pode ser explicitada na ordem da governamentalidade neoliberal, construindo as condições para uma reforma na educação profissional no Brasil e mais especificamente para a criação dos Institutos Federais de Educação.

Para tanto, a problematização deste artigo está em realizar uma leitura analítica da expansão/criação dos Institutos Federais e sua atuação na Educação Básica de Ensino médio integrado à educação profissional e tecnológica, entendendo que esta se constitui em uma estratégia de inclusão que se encontra disposta em documentos internacionais. Neste sentido, a pergunta mobilizadora é: como a disseminação de discurso de inclusão e aprendizagem, presente nos documentos internacionais sobre educação, mobiliza políticas como a criação dos IFs?

Para tal empreendimento, buscamos os e nos documentos internacionais situar discursos que apontem para políticas de reformas na educação e demarcamos a década de 1990 e, mais especificamente os anos 2000, tendo em vista as reformas da Educação profissional, a criação dos IFs e a integração entre ensino médio e educação profissional. Metodologicamente, nos apoiamos em enunciados dos documentos que possam mostrar essas relações, bem como princípios indicadores que movimentam as estratégias de criação de instituições especializadas pela condução da conduta dos jovens.

Empreendemos buscas pelos sites de organismos internacionais tendo como premissa que a educação profissional é parte das práticas discursivas de inclusão e, nesse sentido, selecionamos para a produção desta análise os seguintes documentos:

- Declaração de Educação para Todos, 1990.

- Estratégias do Banco Interamericano para Desenvolvimento do Brasil 20002003.

- Agenda 2020 - BM - aprendizagem para todos: investir nos conhecimentos e competências das pessoas para promover o desenvolvimento.

$\mathrm{Na}$ leitura e análise dos documentos acima, uma noção-ferramenta analítica emergiu com grande potencial: a governamentalidade. Nosso entendimento foi de que a 
governamentalidade, como anuncia seu formulador, Michel Foucault, "não é [...] objeto de estudo [...], pois funciona como um instrumento, como uma ferramenta, como lentes" (NOGUERA-RAMÍREZ, 2009, p. 73) capazes de fazer ver e mostrar como um problema se produz e pode ser pensado. Esse foi o uso que fizemos da ferramenta analítica governamentalidade, ou seja, um uso que teve como metas fazer ver e dizer da educação profissional problematizada por nós, nesses documentos.

Ao olhar, ler e pontuar enunciados desses documentos, construímos a possibilidade de identificar formas de governamento dos sujeitos na contemporaneidade e, mais que isso, de identificar como a educação profissional, desenhada na criação de instituições educacionais, como os IFs, possibilita colocar em funcionamento estratégias que têm o sentido de suprir e direcionar a necessidade e um modo de condução da vida e, por isso, de captura de jovens. Práticas discursivas de um tipo de educação profissional inclusiva e projetada globalmente, tanto como estruturação global dos estados, das instituições, da economia, bem como com a intencionalidade de governar e conduzir os sujeitos. É, assim, um tipo de estratégia a ser operada pelas e nas instituições que orienta um modelo normativo das condutas.

Essa temporalidade histórica expressa pelas décadas de 1990 e 2000 tem a ver com a consolidação da redemocratização do Brasil e sua consolidação como Estado Membro e signatário dos modos de fazer políticas públicas estruturadas nos e pelos organismos internacionais. Mais especificamente, são políticas públicas e princípios que já vinham se consolidando no mundo desde a década de 80. Elas operaram mudanças como a da função do Estado que, de provedor, passa a "[...] prestador de serviço [passando a exercer] uma combinação de regulação, monitoramento de desempenho, contratação e facilitação de novos prestadores de serviços públicos” (BALL, 2014, p. 73), ou seja, colocando em curso a racionalidade de governo neoliberal (RECH, 2010).

É um movimento em que se pode identificar o papel dos organismos internacionais (Organização para Cooperação de Desenvolvimento Econômico OCDE, Fundo Monetário Internacional - FMI, Banco Mundial - BM, Banco Internacional para Reconstrução e Desenvolvimento (BIRD), Organização das Nações Unidas - ONU e Organização das Nações Unidas para a Educação, Ciência e Cultura UNESCO), tanto na economia como na política educacional. E estes estão ocupando funções que antes eram dos Estados e dos governos das nações, criando princípios decisivos às políticas educativas nacionais, com fundamento neoliberal. 
É importante considerar que é entre as décadas de 1990 e 2000 que o Brasil efetivamente se insere na perspectiva de que é o governo da nação que precisa produzir problemas (com o uso das estatísticas) e resolução dos problemas de Estado e da sociedade (economia, mercado, políticas institucionais, sociais, culturais e educacionais de governo e governamento), bem como que isso se articula com novas formas de governo em que se possa colocar em prática as tecnologias políticas globais que produzem "novos agenciamentos de políticas [...] em um novo tipo de espaço de políticas [...] entre agências multilaterais, governos nacionais e negócios internacionais, [para] formulação de políticas" (BALL, 2014, p. 220).

A governamentalidade neoliberal em educação projeta o investimento e a expansão da educação profissional como política pública de inclusão de jovens, ou como uma prática para a resolução dos problemas de Estado e da sociedade. E isso se dá pois a educação profissional é parte das práticas discursivas numa rede global de desenvolvimento econômico e de mercado que se constitui em mais uma forma de lucro quando num "regime de lucro, por meio do empreendimento e do empreendedorismo, [...] para neoliberalizar a educação" (BALL, 2014, p. 223), provocando a "dependência mútua entre mercado e Estado" (p. 47), entre produção e formação de sujeitos.

Como um conjunto de práticas discursivas, concretas, valorativas, de princípios e estratégias, organizadas e utilizadas para a resolução de problemas de Estado e da sociedade, a governamentalidade neoliberal, além de servir como uma matriz supraestatal na acepção de uma política de projeto hegemônico capitalista que produz "cambios específicos que privatizan, liberalizan y despolitizan; forma de Estado, dinámicas que transforman las estructuras estatales mediante competitividad econômica" (SAURA, 2016, p. 14-15), também se configura em uma matriz de governamentalidade de todos e de cada, um tipo de "gobierno a través de tecnologías políticas que conducen las conductas y responsabilizan a los ciudadanos de sus éxitos y fracasos" (SAURA, 2016, p. 14).

É nesse sentido que Saura (2016) recapitula a síntese de Ong (2007), considerando as direções que a governamentalidade neoliberal oferece para a produção de práticas políticas na contemporaneidade: o “«N»eoliberalismo (con «N» mayúscula) [...] y «n»eoliberalismo (con «n» minúscula)" (SAURA, 2016, p. 15). Ou seja, o «N»eoliberalismo como prática político-econômica que projeta e realiza 
[...] cambios desde su condición estructural, política económica o hegemonía ideológica de clase capitalista [...] implican, en la práctica, la desregulación, la privatización y los cambios en la gestión de los servicios públicos estatales. Los trabajos que forman parte de esta corriente exploratoria han comprendido el neoliberalismo como una «ola global», [...] un «tsunami» que ha intentado imponer una ideología a escala planetaria. (SAURA, 2016, p. 15).

$\mathrm{E}, \mathrm{o} \ll \mathrm{n} »$ eoliberalismo como prática que movimenta as relações humanas, sociais e culturais tendo em vista o desenvolvimento e a produção de um tipo específico de sujeitos individuais e coletivos, de modo que:

[...] formas de gobierno neoliberal o «conducción de las conductas» son los nuevos modos de gubernamentalidad del «gobierno de las almas» (Foucault, 1991) [...] como gubernamentalidad o mentalidad de gobierno centra el foco de atención en las formas de ejercer una «gubernamentalización de Estado» (Lemke, 2001) o «gubernamentalización de lo social» (Dean, 1999). Para ello se requieren tecnologías políticas y «racionalidades de gobierno» mediante una «gubernamentalidad activa» (Foucault, 2007: 154) que gobierna para el mercado y se erige para producir la competencia. Las tecnologías políticas coexisten con diversas racionalidades políticas donde el «modo de conducta se rige a través de la libertad», en relaciones interconectadas entre «gobierno, los autos-gobernados y el espacio de administración» (Ong, 2007: 4). La gubernamentalidad neoliberal se sostiene como políticas de Estado que se fundamentan en dirigir la conducta de las conductas a través de estrategias de libertad que responsabilizan a los sujetos de sus aciertos y errores (Burchell, Gordon, \& Miller, 1991; Dean, 1999; Rose \& Miller, 1992). (SAURA, 2016, p. 15).

A educação, e especificamente a formação profissional de jovens, portanto, adjetiva o imperativo da inclusão como uma destas "zonas especiais de desenvolvimento" (ONG, 2009, p. 327) e de tecnologia política que projeta valores de governo e autogoverno que podem, dentro de espaços institucionais, colocar todos dentro e ao mesmo tempo dar limites precisos de como todos e cada um devem se conduzir.

Esse cenário caracteriza um processo de captura e ao mesmo tempo de controle e de identificação dos jovens, um controle dos riscos e uma economia de governo tendo em vista as estratégias de condução das condutas operadas tanto pela liberdade e pela inclusão, como pela responsabilização dos sujeitos por seu próprio desenvolvimento e empreendimento através formação profissional. Para Ong, tratam-se de: 
"'regimes de vida' (regimes of living) - um termo cunhado por Stephen Colier e Andy Lakeoff - que designa ambientes onde as condições políticas, sociais e econômicas entrelaçadas entre si levantam a questão de "como se deve viver"' (2009, p. 328).

As reformas, a expansão, a criação e a implementação das Instituições Federais de Educação Profissional, os IFs, no Brasil, não determinam a história da educação profissional no país, nem podem ser vistos como um processo evolutivo de superação atual de propostas antes existentes; no entanto, provocativamente, buscamos mostrar que a educação profissional ganha força a partir de uma tecnologia política, de uma governamentalidade que se produz em um conjunto complexo de programas, cálculos, técnicas, aparatos, documentos e procedimentos de governo capazes de capturar todos e cada um dos sujeitos em espaços e práticas concretas para que esses se construam e se constituam a partir de finalidades concretas (SAUNA, 2016). E esse quadro é posto tendo em vista que a governamentalidade neoliberal na educação, através de princípios determinados em políticas que se implementam a partir de diretrizes internacionais,

[...] permite que cada um funcione como uma empresa [...] Portanto, nada mais adequado para os neoliberais que ter a educação imersa neste pensamento, e ao mesmo tempo, compactuando com os princípios que visam ao jogo da livre concorrência. Nesse sentido, fazse necessário entrar no jogo [incluir], ou seja, aproximar a escola do mundo do trabalho, na busca por resultados mais expressivos, mais lucrativos, e também na busca por sujeitos que invistam em si mesmos. (RECH, 2015, p. 119).

Adentrando na análise dos enunciados dos documentos internacionais, com um certo detalhamento deles, identificamos certa recorrência de duas palavras diretamente relacionadas ao objetivo deste artigo: "inclusão" e "aprendizagem”. Vislumbramos as políticas de inclusão e a proliferação do discurso em torno da aprendizagem como cenário mundial nos anos 90. Isso não quer dizer que a inclusão e a aprendizagem tenham aparecido de uma vez e finalmente nos documentos internacionais nesse tempo, mas é evidente que emergem com mais força a partir da Declaração Mundial de Educação para Todos (1990).

Nesse primeiro documento, encontramos indícios que mostram a educação profissional e a inclusão como princípios que passam a orientar e a determinar a direção das reformas educacionais no Brasil. A educação para todos pode ser lida como inclusão, no entendimento de Santos (2011, p. 75): 
[...] no Brasil, em consonância com movimento mundial de Educação para Todos, o tema da inclusão tem sido uma das preocupações recentes que fazem parte da pauta das políticas públicas. Os argumentos de tais discussões giram em torno de uma reflexão sobre a inclusão como um processo urgente e necessário para termos uma "verdadeira" educação de qualidade, uma vez que ela tem implicação direta com o desenvolvimento e o investimento em capital humano. Tal discussão [...] refere-se à suposta possibilidade de que com "a inclusão de todos", em tempos de constantes mudanças, a educação se efetive de fato, garantindo o acesso de todos à escola e uma maior qualidade da educação para cada um e para todas as pessoas na sociedade.

A noção de inclusão emerge como uma importante estratégia que movimenta as reformas para alcançar uma educação para todos, passando a ganhar força e se tornando uma grande narrativa. Educação para todos adquire status de verdade tomando corpo nas políticas educacionais, no que se refere a: universalização do acesso à educação escolarizada; criação de instituições escolares que abrem as portas para trazer todos para os espaços educativos e institucionais; captura de todos no discurso do direito à educação e à gestão de uma expectativa para que todos queiram acessar e permanecer em formação e nos espaços educativos, sendo estes identificados e ordenados para produzirem um espaço e tempo para o posicionamento do sujeito em um sujeito aprendente.

Na análise da Declaração Mundial de Educação para Todos da UNESCO, de 1990, é possível identificar que, nas oito páginas do documento, é recorrente a expressão "Educação para Todos", ou termos sinônimos. Nestas diferentes formas de expressão, a expressão "Educação para Todos" aparece relacionada vinte e três (23) vezes com o termo "aprendizagem", e corrobora a ideia de que a educação para todos se articula à lógica da aprendizagem de todos.

Uma das principais referências que nos pareceu importante considerar é que incluir todos e cada um é o mesmo que programar a educação de todos e de cada um tendo como referência primeira o indivíduo para depois o contexto social. Primeiro, é a captura de cada um e sua promoção individual como capital humano o que deriva, $a$ posteriori, o capital que o indivíduo representa para o contexto social. Isso pode ser verificado no trecho: "Políticas de apoio nos setores social, cultural e econômico são necessárias à concretização da plena provisão e utilização da educação básica para a promoção individual e social" (UNESCO, 1990, p. 06, grifos nossos). 
Qualquer política educacional de educação básica, incluindo a profissional, é considerada como um espaço de utilização para que, via aprendizagem, desenvolva-se a promoção individual.

Mesmo que neste documento não apareça uma só vez escrita a palavra "inclusão", observa-se que esta está implícita nas escolhas discursivas feitas na sua elaboração, como podemos observar no seguinte fragmento:

Forças, combinadas com a experiência acumulada de reformas, inovações, pesquisas, e com o notável progresso em educação registrado em muitos países, fazem com que a meta de educação básica para todos - pela primeira vez na história - seja uma meta viável. (UNESCO, 1990, p. 02).

Se a inclusão é uma meta, a aprendizagem se constitui numa qualificação do discurso, tornando-se sinônimo de qualidade de vida: "Estes conhecimentos incluem informações sobre como melhorar a qualidade de vida ou como aprender a aprender" (UNESCO, 1990, p. 02), apostando e projetando o investimento no indivíduo, que, capaz de aprender a aprender e de aproveitar a oportunidade, pode investir em si e se beneficiar de uma educação que visa a:

Contribuir para conquistar um mundo mais seguro, mais sadio, mais próspero e ambientalmente mais puro, que, ao mesmo tempo, favoreça o progresso social, econômico e cultural, a tolerância e a cooperação internacional. (UNESCO, 1990, p. 02).

Incluir e aprender corresponde a uma educação que institucionaliza a todos, a uma Instituição Educacional como espaço cuja atribuição é gestar e tornar necessário o desejo de aprender, que seja capaz de capturar a todos para uma formação, tomando como referência "satisfazer suas necessidades básicas de aprendizagem" (UNESCO, 1990, p. 02). E essas necessidades passam a ser desejadas como se elas fossem necessidades do indivíduo e, com isso, passam a definir quem, e um tipo e um modo de ser do indivíduo no contexto social. Ou seja, necessidades básicas definem e dirigem um modo de ser do indivíduo, capturando-o no sentido de que façam dessas necessidades de aprendizagem suas próprias necessidades, sendo elas:

[...] os instrumentos essenciais para a aprendizagem (como a leitura e a escrita, a expressão oral, o cálculo, a solução de problemas), quanto os conteúdos básicos da aprendizagem (como conhecimentos, 
habilidades, valores e atitudes), necessários para que os seres humanos possam sobreviver e desenvolver plenamente suas potencialidades, viver e trabalhar com dignidade, participar plenamente do desenvolvimento, melhorar a qualidade de vida, tomar decisões fundamentadas e continuar aprendendo. (UNESCO, 1990, p. 02).

A projeção de um documento internacional ali aponta quais são as necessidades básicas de aprendizagem de todos e cada um - aprendizagem que define um contínuo ao longo da vida -, características de ser sujeito que, como afirmam Possa e Naujorks, faz parte de:

[...] redes contínuas de vigilância e controle, subjetivando-nos a encontrar, nos espaços formativos e de atuação, meios para constituir em si e para si competências e habilidades para que possamos ser reconhecidos, adequados, produtores, consumidores e, principalmente, politicamente corretos em relação aos outros e em relação à nossa atuação. (2013, p. 326).

Parece-nos que a aprendizagem pode ser tomada aqui como adequação a uma rede contínua em que a reforma ou criação dos sistemas e das instituições escolares, desde a educação infantil até a educação profissional, passa a fazer parte de uma aliança em que se misturam discursos de inclusão e aprendizagem como forma de captura de todos.

É possível ver dois princípios básicos na Declaração de Educação para Todos, (1990). O primeiro é a inclusão que se traduz na ideia de educação para todos, esta espécie de captura pelo acesso. E o segundo é expresso na ideia de que não basta acessar, tem que a captura se efetivar pela aprendizagem, em uma instituição capaz de “concentrar a atenção na aprendizagem" (UNESCO, 1990, p. 04) e atuar sobre o indivíduo para que ele, aproveitando essas oportunidades, empreenda em si, e aprenda a aprender que precisa incorporar para si as necessidades básicas de aprendizagem que modelam um modo de dizer verdadeiro sobre o sujeito e que adeque sua conduta a uma "formação científica e tecnológica" (UNESCO, 1990, p. 02); ainda que se responsabilize por sua conduta e sua própria inclusão e aprendizagem e, por conseguinte, alcance "um desenvolvimento autônomo" (UNESCO, 1990, p. 02), e que tenha individualmente condições de competir e, com isso, "cave" sua oportunidade no mercado de trabalho, sendo produtivo para si, para sua família e contribuindo com produtividade e com crescimento econômico e social. 
No segundo documento internacional analisado, Estratégias do Banco Interamericano de Desenvolvimento (BID) do Brasil, entre os anos 2000 e 2003 (BID, 2000), encontramos, nas quarenta (40) páginas, a recorrência do termo “desenvolvimento" setenta (70) vezes e do termo "competitividade" vinte e quatro (24) vezes. Nesse documento, a educação está vinculada a uma matriz de ação do BID no Brasil, que elenca os principais desafios que o país precisa enfrentar no período, sendo que "as autoridades nacionais colocaram a educação em lugar de proeminência" (BID, 2000, p. 10).

Assim, a educação é empregada como estratégia e/ou intervenção para o cumprimento dos desafios relacionados a aspectos do desenvolvimento econômico, tendo em vista a redução das desigualdades.

A educação, nesse documento, é estratégia para os desafios do país, sendo tratada a partir de duas óticas, que, mesmo abordadas de forma distinta, estão atreladas uma a outra. Uma ótica relaciona desenvolvimento econômico em que a constituição de sujeitos está relacionada à capacitação dos indivíduos, considerando a necessidade de um upgrade em seus níveis educativos. Outra ótica diz do desenvolvimento dos indivíduos e da população como elemento essencial para o desenvolvimento da economia do país. Assim, a premissa para as políticas de educação passa a ser o crescimento econômico tendo em vista o modo como a educação pode operar a captura dos sujeitos para as instituições e para a formação de empreendedores de si, colocando a aprendizagem como capital/valor econômico.

Isso, na governamentalidade neoliberal, pode ser caracterizado como um modo de captura do sujeito para investimento em si, para desenvolver suas aprendizagens relacionadas ao desenvolvimento do país em relação ao:

- "desafio de melhorar a competitividade" (BID, 2000, p. 36): em um contexto de abertura econômica, a educação é situada como estratégia para a formação e desenvolvimento dos sujeitos para competir globalmente e contribuir com o desenvolvimento econômico.

- desafio do "melhoramento dos níveis educativos [como] condição fundamental para obter os níveis de produtividade e competitividade necessários para o crescimento econômico sustentado" (BID, 2000, p. 10).

- "desafio das desigualdades e da pobreza" (BID, 2000, p. 36), que prevê como ações a "recuperação do crescimento econômico com equidade e reformas para melhorar a 
qualidade de serviços básicos especialmente de saúde e educação" (BID, 2000, p. 36); logo, atribui prioridade à "implantação e aprofundamento de reformas nos setores da educação, saúde, assistência social" (BID, 2000, p. 10).

O documento mostra que, para o BID, a desigualdade e a pobreza (construídas em dados estatísticos) são problemas que não favorecem o crescimento econômico, que travam o desenvolvimento do país, além de elencar a política de educação como solução, tendo especificamente a seguinte orientação: "dará alta prioridade à educação, especialmente de nível secundário e nível técnico profissional” (BID, 2000, p. 37).

Numa conjuntura de consenso mundial que prevê a inclusão educacional como desenvolvimento econômico, as políticas que reformam a educação secundária e profissional são tomadas como possibilidade de acesso a todos e o BID propõe como política educacional para o Brasil a prioridade de investimentos no ensino médio e na educação profissional, que se torna "ferramenta principal para melhorar a distribuição de renda e reduzir a pobreza a médio e longo prazo" (BID, 2000, p. 10), bem como para a recuperação do crescimento econômico.

Com isso, tem-se uma ideia das práticas discursivas e reformistas de onde emergem a necessidade da criação dos programas e da ampliação das instituições, de seu acesso e do número de vagas na educação profissional pública, e da reforma do ensino médio e profissional.

O terceiro documento internacional que trazemos para análise trata das estratégias do Banco Mundial - BM para a educação, a Agenda 2020, que traz como tema 'Aprendizagem para Todos: Investir nos conhecimentos e competências das pessoas para promover o desenvolvimento' (BM, 2011). Já no título, como um slogan, muito convincente, observamos a recorrência de termos que circularam nos demais documentos, tais como: "aprendizagem", "desenvolvimento" e "todos" que incluímos na noção de inclusão.

No corpo desse documento de dezesseis (16) páginas, algumas recorrências são expressivas. O termo "aprendizagem" aparece cerca de 50 vezes e se relaciona com um "período de extraordinária transformação" (BM, 2011, p. 04), citando, como exemplo, a “ascensão dos países de renda média, liderados pela China, Índia e Brasil”. Diz que essa ascensão produz como efeito a intensificação do "desejo de muitas nações de aumentar sua competitividade mediante o desenvolvimento de forças de trabalho mais capacitadas e ágeis" (BM, 2011, p. 06). 
Identificamos que o termo "aprendizagem", ao estar presente com tanta robustez nesse documento, diz respeito ao fato de que, no ano de 2011, por ter a perspectiva inclusiva de acesso já circulada pelas políticas educativas, era necessário acrescentar com maior visibilidade a qualidade de permanência, de modo que a aprendizagem ganha um espaço discursivo de excelência. Diante disso, o que se tem em 2011 é que somente o acesso não possibilitou a inclusão, tornando-se evidente a necessidade de que "todos" que acessaram as instituições educacionais através das políticas de inclusão recebam e possam investir em aprendizagens de qualidade capazes de operar a constituição de indivíduos qualificados e adequados a um modo verdadeiro de ser e se conduzir neste tempo.

O documento pontua, a partir de dados, que há evidências de que "muitas crianças e jovens dos países em desenvolvimento saem da escola sem terem aprendido muito" (BM, 2011, p. 04), sendo este aspecto algo negativo para a economia desses países. Por isso, investir em uma perspectiva de aprendizagem para todos, de educação para todos, é um argumento que se torna produtivo para a ascensão econômica e de desenvolvimento desses países.

Na Agenda 2020, o conceito de aprendizagem para todos é então definido como “a garantia de que todas as crianças e jovens - não apenas os mais privilegiados ou mais inteligentes - possam não só [ir à] escola, mas também adquiram o conhecimento e as habilidades de que necessitam" (BM, 2011, p. 04).

Em um contexto em que aprender e inovar, incluir-se e produzir tem valor primordial, a captura se amplia. Não é mais somente uma captura dos sujeitos para dentro da escola, para estarem nas instituições, pois agora os conhecimentos e as habilidades tidos como verdadeiros e necessários para o desenvolvimento econômico e social são explicitados claramente como necessários para as crianças e os jovens, na proporção de que a noção de aprender passa a ser uma necessidade vital para que estes estejam incluídos.

Como já anunciado, o termo "conhecimento" apresenta-se de forma recorrente no documento, sendo localizado vinte e oito (28) vezes. O termo "conhecimento" está associado ao termo "aprendizagem" e também ao termo "competência": "o crescimento, desenvolvimento, a redução da pobreza dependem dos conhecimentos e qualificações que as pessoas adquirem, não no número de anos que passaram sentados em uma sala de aula" (BM, 2011, p. 07). Isso quer dizer que o tempo escolar não é o primeiro numa sequência de importância, como se vinha enfatizando nas últimas reformas do sistema 
educacional brasileiro (ensino fundamental de nove anos, ensino médio de tempo integral e integrado...), pois o importante é a qualidade de aprendizagem dos indivíduos, os conhecimentos adquiridos, a competência e habilidades para continuar aprendendo de forma qualificada.

Para o BM, devem ser observadas, na composição das políticas educativas de educação profissional, as alterações tecnológicas dos mercados de trabalho, que "[...] estão a mudar os perfis dos empregos requeridos pelos mercados de trabalho" (BM, 2011, p. 06). E, neste sentido, a aprendizagem se torna elemento indispensável para dizer-se da competência do indivíduo, pois "são as competências do trabalhador que determinam a sua produtividade e capacidade para se adaptar a novas tecnologias e oportunidades" (BM, 2011, p. 07).

\section{Considerações finais}

Finalmente, ao trazer para análise os fragmentos discursivos dos três documentos internacionais, tivemos como intensão não esgotar um contexto de influência, mas dar uma mostra de que foi sob os princípios de inclusão e aprendizagem que a educação profissional de nível médio foi se institucionalizando com a intenção da captura dos jovens (acesso de todos) com o objetivo de que sua permanência seja permeada pela aprendizagem que se adeque aos modelos de investimentos em si, na sua formação. Entramos em contato com discursos apelativos da esperança de que, ao finalizar o curso, esse jovem vai ter uma profissão, e, nesse movimento formativo, temse a possibilidade de um governamento da conduta para que se mantenha em aprendizagem, pois aprender tem valor numa conjuntura neoliberal.

Incluir e aprender são, assim, características das instituições, e para isso os IFs foram criados, um empreendimento em instituições por todo o país e em reformas do Ensino Médio, integrando-o à educação profissional como forma de governo de parte da população, para uma juventude que no presente e no futuro se apresente adequada e produtiva. Preparar-se para o trabalho, adequar-se ao sistema produtivo, ser capaz de produzir individualmente e aprender sempre com as mudanças do sistema é parte do empreendimento institucional que exige de todos e de cada um empreendimento individual. $11.892 / 2008$,

É assim que se fundam por efeito a função institucional dos IFs, na Lei 
[...] a justiça social, a equidade, a competitividade econômica e a geração de novas tecnologias. Responderão, de forma ágil e eficaz, às demandas crescentes por formação profissional, por difusão de conhecimentos científicos e tecnológicos e de suporte aos arranjos produtivos locais. (BRASIL, 2010, p. 03).

Incluir e aprender a constituir um sujeito com condições de inserir-se e manterse no mercado de trabalho, competir para exercer uma determinada atividade subsidiado pelo conhecimento construído, mas, principalmente, pelo investimento em aprender, constitui capital passível de novos investimentos e de produtividade. Isso implica que o papel institucional dos IFs está em tomar a formação do jovem sob a ótica do profissional como meio para sua adequação, produtividade, competências e habilidades reconhecidas e condicionadas como necessidades, para que eles possam alcançar um lugar ao sol, mas não eternamente, porque, para manter-se ao sol, incluído, é preciso aprender continuamente, investir em si ad eternum e, para isso, os IFs ampliam sua atuação com outros programas e processos formativos, atuando no PROEJA, nos Cursos de Tecnólogo, no PRONATEC...

No contexto de uma governamentalidade neoliberal, a orientação dos organismos internacionais em seus documentos é que países em desenvolvimento invistam intensamente em educação básica para não ficar na contramão do desenvolvimento econômico mundial numa conjuntura econômica globalizada, pois, com a inovação tecnológica e a circulação cada vez maior da informação, é vital uma educação que capacite todos para competir no mercado. A qualificação profissional, portanto, é condição mister de um sujeito constituído de competências e habilidades para a aprendizagem continuada, que domine noções básicas que lhe deem condições de adaptar-se às mudanças de forma rápida, de solucionar problemas, de operar com capacidades de iniciativa e decisão de forma produtiva para esse mercado. Isso justifica as metas do BID para o Brasil abaixo citadas:

[...] desenvolvimento e a expansão da educação primária, (graus 1 a 8), melhoria e expansão da educação média (graus 9 a 11)], e reforma do ensino profissional (educação para o trabalho), [...] melhoramento da qualidade do ensino, especialmente do ensino médio como nível que prepara os alunos para enfrentar o mundo do trabalho. (BID, 2000, p. 25).

Neste sentido, a expansão das escolas técnicas, reformadas como Institutos Federais e da Rede Federal de Educação Profissional, pode ser lida como cumprimento 
de metas de um projeto neoliberal orientado pelos organismos internacionais, e isso se confirma com o fragmento do documento do BID, quando diz: "expansão do sistema educativo concentrando esforços no ensino médio, com ênfase em medidas que favoreçam o acesso aos grupos menos favorecidos” (BID, 2000, p. 25). Ou, ainda, essa meta é confirmada ao reforçar a ideia de ampliação do alcance das redes de captura para que nenhum jovem fique de fora, para que todos estejam incluídos em uma ampliação que atinge a todos, que traz todos para dentro das instituições escolares, considerando-se a Declaração Mundial de Educação para Todos que compromete o Brasil a "ampliar os meios de e o raio de ação da educação básica" (UNESCO, 1990, p. 05).

A circulação de uma ideia de 'educação para todos' traz para a necessidade de escolarização e profissionalização que empreender em si é "aprender a diluir-se, fazer parte do jogo social, ser cambiável, manter-se desejante e consumidor” (RECH, 2010, p. 81), colocando em movimento aquilo que, no neoliberalismo, é princípio: participação de todos nos jogos de consumo e produtividade.

Participar do jogo, aprender ao longo da vida, aparece articulado com as reformas da educação profissional no Brasil, uma era do Homo discentis; esse sujeito contemporâneo é um eterno estudante desejoso de formação e mais formação, essa condição de ser um aprendente ao longo da vida e por toda a vida (NOGUEIRARAMÍREZ, 2009).

Assim, é possível identificar que a criação dos IFs pode ter algo de criativo localmente, mas, sobretudo, é linha diretiva de atuação dos organismos internacionais, na formulação das políticas educacionais brasileiras. A educação profissional via IFs que, "alinhada com as políticas de inclusão e com um projeto de nação" (BRASIL, 2010, p. 39), toma um modelo de necessidades de aprendizagem, de habilidades e competências regulador de todos, regrando os desejos, os modos de ser e de conduzir a vida e conduzir os outros.

\section{REFERÊNCIAS}

BRASIL. Instituto Federal de Educação, Ciência e Tecnologia: um novo modelo em educação profissional e tecnológica - concepção e diretrizes. Brasília: SETEC - MEC, 2010 .

BANCO MUNDIAL. Aprendizagem para Todos: investir nos conhecimentos e competências das pessoas para promover o desenvolvimento. Banco Mundial, 2011. 
BID. Estratégias do Banco Interamericano para o Desenvolvimento do Brasil entre os anos 2000 e 2003. Banco Interamericano para o Desenvolvimento, 2000.

ETCHEVERRY, Daniel e JARDIM, Denise. “Entrevista com Aihwa Ong”. In:

Horizontes Antropológicos, Porto Alegre, ano 15, n. 31, jan./jun. 2009, p. 321-328.

FOUCAULT, M. Segurança, território, população. São Paulo: Martins Fontes, 2008.

GADELHA, S. Biopolítica, governamentalidade e educação: introdução e conexão a partir de Michel Foucault. Belo Horizonte: Autêntica, 2009.

LÓPEZ-RUÍZ, O. Os executivos das transnacionais e o espírito de capitalismo: capital humano e empreendedorismo como valores sociais. Rio de Janeiro: Azougue, 2007.

LYOTARD, J-F. O pós-moderno. Rio de Janeiro: José Olympio, 1988.

NOGUERA-RAMIREZ, C. O Governamento Pedagógico: da sociedade do ensino para a sociedade da aprendizagem. 2009. 266 p. Tese (Doutorado em Educação) Universidade Federal do Rio Grande do Sul, Porto Alegre, RS, 2009.

POSSA, L. B.; NAUJORKS, M. I. Efeitos da racionalidade neoliberal nos discursos sobre inclusão: o silêncio docente. Revista Educação, Santa Maria, v. 38, n. 2, p. 319328, 2013.

RECH, T. L. A emergência da inclusão escolar no Governo FHC: movimentos que a tornaram uma verdade que permanece. 2010. 182 p. Dissertação (Mestrado em Educação) - Universidade do Vale do Rio dos Sinos, São Leopoldo, RS, 2010.

RECH, T. L. Da escola à empresa educadora: a inclusão como uma estratégia de fluxo-habilidade. 2015. 259 p. Tese (Doutorado em Educação) - Universidade Federal do Rio Grande do Sul, Porto Alegre, RS, 2015.

SANTOS, Y. B. S. As políticas de educação para a pessoa com deficiência: a proposta dos Institutos Federais de Educação, Ciência e Tecnologia. 2011. 110p. Dissertação (Mestrado em Educação) - Universidade Federal do Ceará, Fortaleza, CE, 2011.

SAURA, G. Neoliberalismo como discurso. La evaluación en educación entre tecnologías políticas neoliberales y la nueva filantropía. Revista Educação, Sociedade \& Culturas. n. 47, 2016, p. 11-30.

UNESCO. Declaração Mundial sobre Educação para Todos: satisfação das necessidades básicas de aprendizagem. Jomtiem: UNESCO, 1990. 


\section{Como referenciar este artigo}

GATTERMANN, Beatris.; POSSA, Leandra Boer. Inclusão e Aprendizagem como Imperativos da Governamentalidade Neoliberal e a Criação dos Institutos Federais de Educação no Brasil. Revista Ibero-Americana de Estudos em Educação, Araraquara, v. 13, n. 4, p. 1632-1651, out./dez., 2018. E-ISSN: 1982-5587. DOI: 10.21723/riaee.unesp.v13.n4.out/dez.2018.11057

Submetido em: 19/02/2018

Aprovado em: 15/07/2018 